\title{
Research on Application of Regional Culture Symbols in the Design of Seat Pattern of High-Speed Train
}

\author{
Fan Juan ${ }^{1 *}$, Chen Wei ${ }^{12}$ \\ ${ }^{1}$ University for Science \&Technology Sichuan, Chengdu in Sichuan 611745, China \\ ${ }^{2}$ Southwest Jiaotong University Chengdu 610031, China \\ Eml:hattcv0909@qq.com
}

\begin{abstract}
In modern design, the culture of the product makes the product rich in connotation more and the Designers begin to design from the perspective of culture. This paper illustrates the research status of the pattern design and analyzes the functions and effects of the symbols from the signifier, signified. Based on the definitude of the connotation of regional culture symbols, three kinds of extraction methods of regional culture symbols for reconstruction, decomposition combination and simplified extraction of elements are summarized and arranged. Based on the connotation of regional culture and extraction methods of symbols, the extraction and application of seat pattern elements of high-speed train in Chongqing are analyzed and researched.
\end{abstract}

Key Words: regional culture, symbol, high-speed train seat, pattern design

\section{O Introduction}

The high-speed train designed and developed by China shall be able to reflect the characteristics and demand of China naturally. China is a time-honored country and has created brilliant Chinese culture in a period of several thousand years. The prototype is sourced from the content contained in these traditional cultures from the perspective of design, refined and processed into Chinese color elements as well as modeling elements and incorporated into the design and research of the high-speed train to reflect the Chinese characteristics of the Chinese high-speed train comprehensively [1]. With increasingly widespread communication for information between Chongqing and outside world, more and more attention has been paid to the creative product design that gives play to the advantages of cultural knowledge resources, builds the creativity and inspiration, develops the innovation and takes the regional culture as medium in achieving the regional economic development. The creative design with local characteristics is an important way to inherit regional culture and promote the development of regional economy [2]. The Paper, based on the regional culture in Chongqing, discusses the application of regional culture symbol in the design of seat pattern of high-speed train.

\section{Design status of train seat finish at home and abroadZ}

The symbol plays an important role in the influence of the culture on the outside world. The person is the symbolic animal and the symbolic thinking has become one of the basic tools for human expression and communication [8]. The people recognize the culture by the symbol and the generation of the culture and civil are depended on the symbol. It is precisely because people have the ability to use symbols that culture can exist. Symbols are the communication tools between all kinds of forms of the culture. Before conducting the local design, the Designer shall investigate the representation and connotation of the traditional culture in depth to express the culture information through the proper design by all kinds of thinking method and design method. Although the regional traditional culture is rich and colorful, it still needs to discard the dross and select the essential and can be applied in the design after selective 
transformation [9]. Concretely, the method of regional cultural symbol reconstruction, decomposition and combination, element simplification and extraction can be adopted.

\section{Reconstruction and transformation of regional culture symbol}

The reconstruction is to reorganize the traditional elements into new visual image creatively by separation, cutting, scattering, dislocation, positive and negative forms and other forms of means in accordance with a certain aesthetic rules and creation idea [10]. By the reconstruction of the regional culture symbol, the form must reflect the characteristics of regional symbol and meet the aesthetic rules at present, so that the product with a unique style that is regional and stylish can be ensured.

\section{Decomposition and combination of regional culture elements}

The decomposition and combination is the recombination of the complicated regional cultural symbols after decomposition simplification or transformation, based on the modern aesthetic idea [11]. After obtaining the design inspiration from regional culture symbol, the Designer shall deal with the complicated design patterns by the method of decomposition and combination to achieve the reservation of the charm of peculiar regional culture symbol and the possession of characteristics of modern terse style, thus meeting the aesthetic demand of the user to pursue the simple.

\section{Simplification and extraction of regional culture symbol}

The simplification and extraction is the method of transformation and arrangement for regional culture symbol, and the simplification is not the hasty deletion but a kind of recreation behavior to extract the quintessence. That is to handle the complicated design patterns to omit the tedious and antiquated details, highlighting its characteristics, and the charm of pattern shall be extracted by exaggeration and modification and other techniques, so that the design patterns are simple and elegant, but the decorative beauty of the original patterns is not lost. By the recreation of typical characteristics of regional symbols in the seating finish design, it may have a stronger vitality, infection and sense of the times, thus achieving vivid effect.

\section{Extraction and application of design elements of seating pattern of high-speed train based on regional culture in Chongqing}

Bayu culture is a part of long standing of Chinese traditional culture, with 3000 years of history, and the special Bayu culture is portrayed in this land. This research starts from the geography, climate, ethnic, industrial, agriculture, business, animal and plant and other ways of Chongqing. The inland topography of Chongqing is dominated by the mountains and the Yangtze River runs across all areas. The average elevation is $300-400 \mathrm{~m}$, creating a high and low scattered, tier upon tier and beautiful mountain scenery, known as "Fog Chongqing". Chongqing is one of the areas of most abundant biological species in the State and the plant resources in Jiangjin Simian Mountain Nature Reserve with virgin forest characteristics are abundant. The cathaya, du juan wangshu, big-leaf tea and square bamboo shoots are famous at home and abroad.

After the author analyzes the Chongqing culture, some representative symbols are found, such as: square bamboo shoots, Chongqing city flower - camellia. The camellia is the theaceae, with characteristics of evergreen dungarunga, long flowering period, anti-pollution and cultivation easy and with 73 kinds of variety and bright-colored flower color, including light red, purple, red, white, etc. The 
types of petal include single, compound heart opened, anemone, petal curved, and half- flat and flat. The camellia has a history of more than 2000 years cultivated in Bashu area. In 1986, the camellia was officially named as the city flower of Chongqing.

The camellia is selected as the object of element extraction in this time, of which the shape and color are analyzed and the form is abstracted as a geometric pattern, and then the formed pattern shall be applied to the seating cloth cover of high-speed train.

Scheme I: The simplification shall be conducted by making use of the characteristics of natural appearances of the camellia, so that the pattern structure is simple, with clear lines, and the characteristic of rounded bowl of camellia flowering shape is more obvious, added the decorative lines in the part of obvious characteristic for decoration. Covered with a great circle is a kind of symbol of perfection. The auxiliary graph is abstracted from the oval form of the camellia's leaf and the color collocation is overflowing with affection, romantic and tranquil. The plane pattern design is completed by the continuous arrangement and applied in the design of seat finish, shown in Fig 1 and Fig 2.
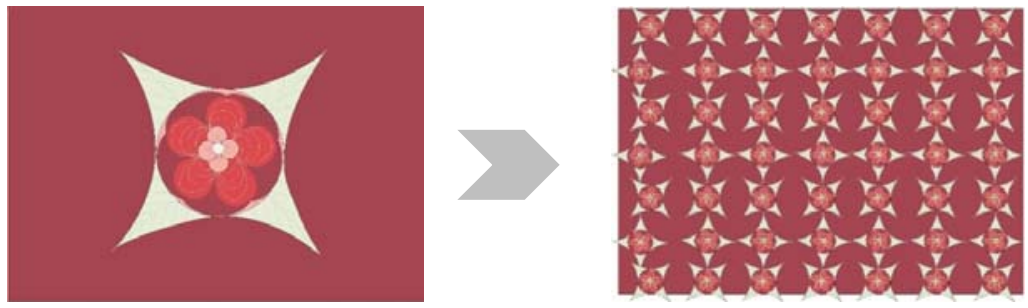

Fig 1 Pattern Extraction and Application Process

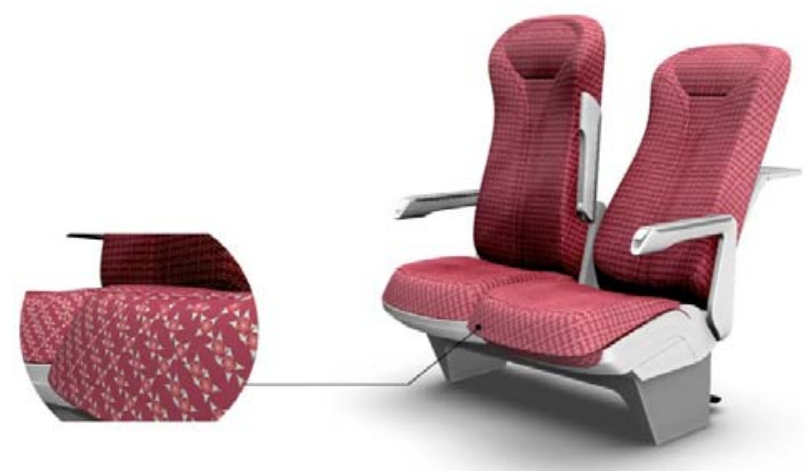

Fig 2 Effect Picture of Seat Scheme I

Scheme II: The outer contour form of the camellia's leaf shall be summarized and reconstructed, and conducted partial exaggeration treatment to present a unique pattern. The fresh, beautiful and concise shape and the patterned design carried out in the form of geometry can better reflect its bright and vivid decorative effects. The middle line graph is surrounded by four dots, showing a balance beauty, and the use of jumping orange color, contrasting strong, enchanting extraordinary, full of vitality and vitality is a kind of high tone collocation, of which the whole effect is obvious and will not seem too exaggerated. The single element extracted from the pattern completes the plane pattern design by the continuous arrangement and applied in the seat pattern to active the whole travel environment of the train to a higher degree. See Fig 4 and Fig 5. 

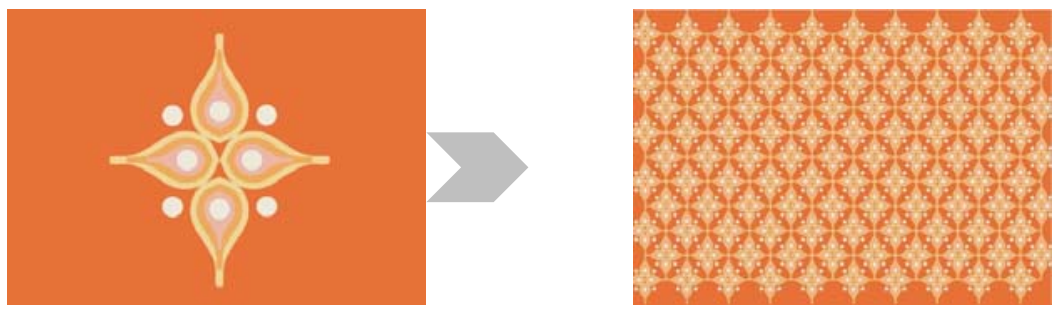

Fig 3 Pattern Extraction and Application Process

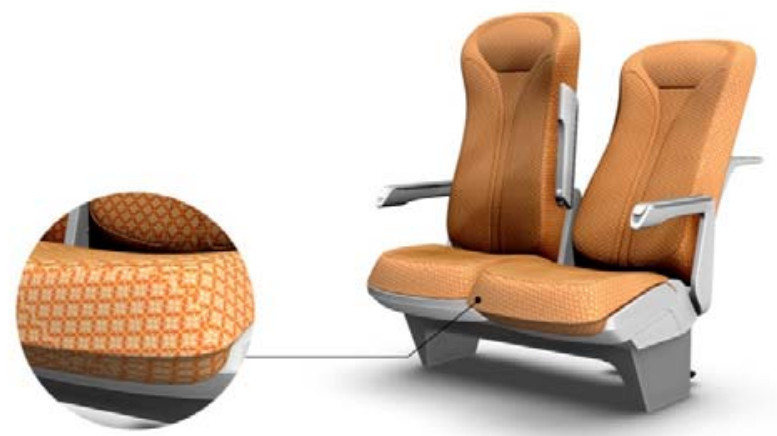

Fig4 Effect Picture of Seat Scheme II

\section{Conclusion}

The regional culture symbol is abundant and the technique to apply the symbol to the industry design is also diversified, as the Designer, only when we study the regional cultural symbols carefully can we design the design works with regional characteristics. The Paper, starting from the characteristics of regional culture in Chongqing, combined with the three methods of extraction of regional culture symbol, extracts the representative pattern elements to be applied in the design of seat finish pattern of high-speed train. I hope to provide some reference for the application of regional culture in the design of seat patterns of high-speed trains.

\section{Acknowledgement}

The general project of provincial education department of Sichuan, project number: 17SB0335.

\section{References}

[1] XIANG Ze-rui, XU Bo-chu \& ZHI Jin-yi 2013. Review and Prospect of Research of Industrial Design of High- speed Train in China. Journal of the China Railway Society, vol.35, issue 12, p.15.

[2] CHEN Liang \& TANG Shan 2016. Innovation Design of Tourist Souvenirs Based on the Han Culture Elements of Xuzhou. Packaging Engineering, issue 12, p.122-125.

[3] ZHI Jin-yi \& XU Bo-chu 2007. Discussions on the Humane Interior Designs of Passenger Train. Journal of Southwest Jiaotong University (Social Sciences), vol. 8, issue 1, p.27-30.

[4] Zhong-ping \& Yang 2012. Shinkansen Talk about: Japan's High-Speed Rail Technology. China Railway Publishing House.

[5] Yong-xiang liu 2008. Product Design. Beijing: Mechanical Industry Publishing House.

[6] Zhi-chun li 2010. Product Design Intention of Cultural Symbol Study. Journal of packaging engineering, p. 16-17. 
[7] Xu Bo-chu \& ZhangYong 2013. Urban Public Transportation Systems Regional Culture Study. Journal of literature and art research, issue 6, p.163.

[8] Li jing 2012. Quanzhou local application in the transformation of creative product design. Journal of Cultural Symbols in Western Leather, issue 1, p.34.

[9] Bo-Chu Xu, Wang Chao \& XIANG Ze-rui 2014. Considering the Regional Culture of Urban Public Transport System Image Research. Journal of Art Observation, issue 8, p.130-131.

[10] Zheng Guiyu 2007. Generalize Traditional Graphic Elements Modern. Journal of New Art, vol.28, issue 1, p.103- 105.

[11] Liu Yuan 2009. Based on Morphological Decomposition of Matrix Elements of the Advertising Creative Research. Hubei University of Technology.

Author introduction: Fan Juan (1982.2 -), female, Guanan Sichuan, science and technology vocational college of Sichuan, lecturer, research direction: graphic design, product packaging design. Tel:+8618080923575

Author introduction: Chen Wei(1983.2-), male, Xiangyang Hubei ,graduate student, lecturer, main research direction for product design theory research. Tel:+8613438102906 